\title{
Funksies van voorbeeldmateriaal in eentalige woordeboeke*
}

\author{
L. Rademeyer, Buro van die Woordeboek van die Afrikaanse Taal, \\ Stellenbosch, Suid-Afrika
}

\begin{abstract}
Functions of Illustrative Material in Monolingual Dictionaries. Illustrative material is a microstructural element which in most dictionaries is not used to its full potential. Interaction between examples and other microstructural elements is imperative. Correlation between the definiens and illustrative material in the dictionary article aids the user of the dictionary with his encoding skills. Without illustrative material supporting it the information conveyed by the definiens is not as significant as it could be. However, illustrative material should not be viewed as an only means of conveying semantic information. Correlation between usage labels and examples is especially important. An example which contradicts a label, or vice versa, confuses the user. If either label or illustrative material is absent, the user can easily be misled. Illustrative material should also support the grammatical information given in the dictionary article. It has an implicit function because it complements and illustrates the explicit information. A correlation between these two microstructural elements of the dictionary article will result in a dictionary which is more user-friendly. Both citations and constructed examples can be applied successfully to assist the user in the comprehension and generation of utterances. Furthermore examples shows that each lexical item is related to others semantically as well as syntactically. Certain semantic resemblances and differences between related lexical items are reflected by illustrative material. Illustrative material should not be viewed as an optional element of the dictionary article, but as an essential component thereof.
\end{abstract}

Keywords: CITATIONS, CONSTRUCTED EXAMPLES, CONTEXT, DEFINIENS, DICTIONARY ARTICLE, DICTIONARY USER, EVIDENCE OF USAGE, EXAMPLES, GRAMMATICAL INFORMATION, ILLUSTRATIVE MATERIAL, INTERACTION, LEMMA, LEXICAL ITEM, PRAGMATIC, REGISTER, SEMANTIC, SEMANTIC RELATIONS, SYNTACTIC USAGE

Opsomming: Voorbeeldmateriaal is 'n mikrostrukturele element van die woordeboekartikel wat in die meeste woordeboeke nie tot sy volle reg kom nie. Interaksie tussen voorbeelde en ander mikrostrukturele elemente is noodsaaklik. Korrelasie tussen die definiens en voorbeeldmateriaal in die woordeboekartikel help die woordeboekgebruiker met sy enkoderingsvaardighede. As 'n definiens nie deur voorbeeldmateriaal ondersteun word nie, is die inligting wat daarin vervat is, nie so betekenisvol as wat dit kan wees nie. Voorbeeldmateriaal behoort egter nooit as enigste definiëringsmeganisme op te tree nie. Korrelasie tussen gebruiksetikette en voorbeelde is veral

Hierdie artikel is 'n verkorte en aangepaste hoofstuk wit 'n M.A.-tesis, Die funksies van verbale voorbeeldmateriaal in eentalige woordeboeke, wat in Januarie 1992 deur die Universiteit van Stellenbosch anvaar is. 
belangrik. 'n Voorbeeld wat 'n etiket weerspreek, of omgekeerd, verwar die gebruiker. Indien óf etiket óf sitaat ontbreek, kan die woordeboekgebruiker maklik mislei word. Voorbeelde behoort ook die grammatiese inligting in die woordeboekartikel te ondersteun. Dit het in implisiete funksie in hierdie geval, aangesien dit die eksplisiete inligting aanvul en illustreer. 'n Woordeboek waarin hierdie twee mikrostrukturele elemente korreleer, is gebruikersvriendelik. Sowel sitate as poëme kan suksesvol gebruik word om die gebruiker te help met die verstaan en voortbring van taaluitings. Verder toon voorbeeldmateriaal ook aan dat elke leksikale item op semantiese sowel as sintaktiese vlak verwant is aan ander leksikale items. Dit weerspieël ook bepaalde semantiese ooreenkomste en verskille tussen verwante leksikale items. Voorbeeldmateriaal behoort nie as 'n bykomende element van die woordeboekartikel beskou te word nie, maar as in noodsaaklike komponent daarvan.

Sleutelwoorde: BETEKENISBETREKKINGE, BEWYS VAN GEBRUIK, DEFINIENS, GRAMMATIESE INLIGTING, INTERAKSIE, KONTEKS, LEMMA, LEKSIKALE ITEM, POëME, PRAGMATIES, REGISTER, SEMANTIES, SINTAKTIESE GEBRUIK, SITATE, VOORBEELDE, VOORBEELDMATERIAAL, WOORDEBOEKARTIKEL, WOORDEBOEKGEBRUIKER

\section{Inleiding}

Voorbeeldmateriaal kan verbaal of nie-verbaal wees. Verbale voorbeeldmateriaal sluit eenwoordsitate, kollokasies en voorbeeldsinne in. Nie-verbale voorbeeldmateriaal verwys na illustrasieprente, grafieke en soortgelyke hulpmiddels. In die bespreking wat volg, word slegs die funksies wat verbale voorbeeldmateriaal as mikrostruktuurelement van die woordeboekartikel verrig, gedek. Wanneer daar dus na voorbeeldmateriaal verwys word, gaan dit om verbale voorbeeldmateriaal.

Volgens Wiegand (1988: 52) is die woordeboekartikel 'n geordende versameling leksikografiese tekssegmente en/of teksboustene waarby die lemma die verpligte teksbousteen is. Indien die woordeboekartikel so beskou word, vorm die voorbeeldmateriaal een van die tekssegmente waaruit dit opgebou is. Elke stuk inligting wat 'n inskrywing in die woordeboekartikel vorm, vorm ook 'n tekssegment of -bousteen daarvan. Dit is noodsaaklik dat hierdie tekssegmente mekaar aanvul en dat daar ' $n$ eenheidskarakter tussen hulle bestaan. Voorbeeldmateriaal speel ' $n$ belangrike rol in die bewerkstelliging van hierdie eenheidskarakter. Die voorbeeldmateriaal in 'n woordeboekartikel sê iets meer oor die lemma as element van die woordeskat. Hierdie inligting is van groot belang. Hoewel dit implisiete inligting is, kan die weglating daarvan die woordeboekgebruiker van belangrike inligting ontneem.

In hierdie artikel word onder andere gepoog om aan te toon dat voorbeeldmateriaal die eksplisiete inligting wat in die woordeboekartikel gegee word, op verskillende vlakke ondersteun. 


\section{Wisselwerking tussen voorbeeldmateriaal en definiens}

Voorbeeldmateriaal en definiens is twee tekssegmente wat nie onafhanklik van mekaar kan optree nie. 'n Woordeboekartikel is onvolledig indien daar nie voorbeeldmateriaal is wat die inligting wat in die definiens gegee word, aanvul en illustreer nie. Dit moet beklemtoon word dat voorbeeldmateriaal nie daar is om leemtes in die definiens te ondervang nie. Dit dien as ondersteunende element by ' $n$ volledig gedefinieerde lemma of betekenisonderskeiding daarvan.

\subsection{Alleenstaande definiens}

Wanneer ' $n$ definiens verskaf word wat nie met voorbeeldmateriaal aangevul word nie, is die inligtingsoordrag onvolledig. Indien die woordeboekgebruiker van óf 'n sinoniemdefinisie óf 'n betekenisomskrywing voorsien word, en dit nie aangevul word met 'n praktiese illustrasie van die gebruik van die lemma nie, is die definiens van minder waarde. Die afwesigheid van ' $n$ wisselwerking tussen definiens en voorbeeldmateriaal veroorsaak ' $n$ verskraling van die inligting wat die gebruiker uit die woordeboekartikel kan ontsluit. Vergelyk in hierdie verband Lombard (1992: 161) se uitspraak dat die enkoderende funksie van voorbeeldmateriaal nie geringgeskat moet word nie.

Die definiens wat by betekenisonderskeiding 1 van moeilik in Nasionale Woordeboek (voortaan NW) voorkom, is wat inspanning vereis. Aangesien dit nie deur voorbeeldmateriaal aangevul word nie, is dit nie duidelik ten opsigte van watter tipe(s) naamwoord(e) die woord moeilik in hierdie betekenis gebruik kan word nie. 'n Kort, deursigtige voorbeeld soos ' $n$ moeilike som sou hier van waarde wees om 'n tipiese attributiewe gebruik van moeilik saam met 'n selfstandige naamwoord te illustreer. Vergelyk ook die werk was baie moelik ("dit het groot inspanning vereis") as voorbeeld van 'n predikatiewe gebruik van moeilik.

Vergelyk ook die volgende definiens wat by die vierde betekenisonderskeiding van plak II in NW gegee word: jou vestig. Aangesien hier geen voorbeeldmateriaal of etikettering is nie, kan die woordeboekgebruiker die aanname maak dat plak in hierdie betekenis in enige konteks gepas sou wees. $\mathrm{Na}$ analogie van die inligting wat verskaf is, kan ' $n$ sin soos die volgende verkeerdelik gevorm word: Piet plak in Kaapstad vandat hy daar werk. 'n Vollediger definiens en duidelike illustrasievoorbeelde sou hier help om 'n wisselwerking tussen definiens en voorbeeld te bewerkstellig. As definiens kan byvoorbeeld 'n omskrywing soos die volgende gegee word: jou onwettig of. sonder die toestemming van ander inwoners of eienaars in 'n gebied vestig. 'n Voorbeeld soos die volgende sou hier nuttig gewees het: Die hawelose mense het sommer op die vlakte begin plak, en nou is daar ' $n$ plakkersdorpie. 


\subsection{Voorbeeldmateriaal sonder definiens}

Voorbeeldmateriaal moet nooit as enigste definiëringsmeganisme aangewend word nie. Dit behoort gebruik te illustreer, ter aanvulling van 'n definiens wat betekenisleiding verskaf.

In die negende uitgawe van Samuel Johnson se woordeboek $A$ Dictionary of the English Language word voorbeeldmateriaal in die vorm van sitate soms as enigste definiëringsmeganisme aangewend. Dit kom volop voor, byvoorbeeld by die volgende lemmas: abdomen, cartilage, macaw-tree, marrow en stablestand. In sommige gevalle het sulke sitate ortografies die vorm van 'n definiens. Tog word dit van inligting soos die naam van die outeur voorsien. Dit gaan hier om 'n vermenging van betekenis- en gebruiksleiding. Hierdie ontsporing van inligtingsaanbieding kan die woordeboekgebruiker grootliks verwar.

Die implikasie van hierdie werkswyse is dat dit aan die woordeboekgebruiker oorgelaat word om sowel betekenis- as gebruiksinligting uit die sitate te haal en hierdie twee inligtingstipes van mekaar te skei. Daar word hoë eise aan die woordeboekgebruiker gestel, aangesien hy nou self die leksikograaf se siftingstaak moet uitvoer terwyl eersgenoemde voorsiening moes gemaak het vir duidelik'omlynde definiense en voorbeelde. 'n Bondige definiens, met die noodsaaklikste inligting, aangevul deur 'n voorbeeld waarin die lemma se gebruik in die taal geillustreer word, sou beter leiding verskaf.

\subsection{Gebrekkige definiens plus voorbeeld}

Indien die leksikograaf streef na 'n volkome wisselwerking tussen voorbeeld en definiens, behoort hy altyd te poog om eers volledige betekenisleiding te verskaf. Daar kan nie vir gebrekkige definiëring vergoed word deur die verskaffing van uitgebreide voorbeeldmateriaal nie. Dit behoort nie vir die woordeboekgebruiker nodig te wees om betekenisinligting in die voorbeeldmateriaal te gaan soek nie. Elkeen van hierdie mikrostruktuurelemente behoort hul eie funksie en plek in die artikel te beklee.

\section{Wisselwerking tussen die aanduiding van styl- of registervlak en voorbeeldmateriaal}

Waar 'n lemma geëtiketteer is en dus in die een of ander opsig afwyk van die standaardtaal, behoort daar voorbeeldmateriaal te wees ter ondersteuning van die inligting wat per etiket verskaf is. Indien óf voorbeeld óf etiket ontbreek, kan hierdie twee mikrostruktuurelemente mekaar nie aanvul nie.

Dit is ook noodsaaklik dat voorbeeldmateriaal en etiket met mekaar korreleer. Vergelyk die artikel van blotto in die Longman's Dictionary of Contempora- 
ry English (voortaan LDOCE): Old John was really blotto last night. Die etiket wat gegee word, is BrEng $\mathrm{sl}$. Die voorbeeldsin illustreer die inligting wat eksplisiet deur die etiket daargestel is op 'n praktiese wyse. Hier is dus wel 'n wisselwerking tussen etiket en voorbeeldsin. Die twee mikro-inskrywings korreleer met mekaar en verskaf nuttige leiding aan die woordeboekgebruiker.

Dit behoort ook nie vir die woordeboekgebruiker nodig te wees om uit die voorbeeldmateriaal af te lei dat die lemma geëtiketteer moes gewees het nie. Indien dit nodig sou wees, is onvolledige leiding verskaf. By die lemma gawk in LDOCE word die volgende voorbeeld gegee: Don't gawk at it, do something! 'n Moedertaalspreker van Engels sou waarskynlik kon aflei dat 'n etiket soos infml (d.i. informal) hier nodig is. Dat die etiket ontbreek, is egter 'n tekortkoming.

In 'n aanleerderwoordeboek is etikettering van die allergrootste belang, aangesien die gemiddelde gebruiker van so 'n woordeboek nie oor moedertaalsprekerintuîsie ten opsigte van die taal wat hy aanleer, beskik nie. Daar kan dus nie van die woordeboekgebruiker verwag word om aannames te maak met betrekking tot gebruik of enige ander aspek van die taal nie: die inligting moet eksplisiet gegee word.

\section{Wisselwerking tussen eksplisiete en implisiete grammatiese inligting}

Dit is noodsaaklik dat daar in elke woordeboekartikel grammatiese inligting verskaf sal word. Hierdie inligting word eksplisiet as afsonderlike mikrostrukturele inskrywings aangebied. Voorbeeldmateriaal verskaf implisiete grammatiese inligting, met ander woorde dit ondersteun en illustreer die eksplisiete grammatiese inligting wat per opmerking of etiket gegee is. Gouws (1989:230) noem dat voorbeeldsinne 'n illustrasie van tipiese grammatiese patrone moet bied.

'n Voorbeeld van eksplisiete grammatiese inligting wat by werkwoordelike lemmas verskaf behoort te word, is die plasing van die verledetydsmorfeem ge- om die verledetydsvorm van die werkwoord te vorm. By deeltjiewerkwoorde moet byvoorbeeld aangetoon word dat die verledetydsmorfeem getussen die werkwoordelike deel en die deeltjie geplaas moet word. Indien 'n voorbeeldsin of -frase hierdie inligting prakties illustreer, korreleer die eksplisiete en implisiete inligting met mekaar. Die woordeboekgebruiker word terselfdertyd ook van 'n praktiese illustrasie van die eksplisiete inligting voorsien.

In NW word die eksplisiete grammatiese inligting, naamlik die aandui van die plasing van ge- by deeltjiewerkwoorde dikwels nie aangevul met voorbeeldmateriaal nie. Vergelyk die lemmas hokslaan, stokkiesdraai, visvang, voetslaan en weglaat. Sulke woordeboekartikels is onvolledig. Ter wille van sintaktiese leiding is dit veral noodsaaklik om volsinne by sulke lemmas as voorbeelde te gee. 


\section{Sitate as bewysmateriaal}

Sitate, dit wil sê voorbeelde van aangehaalde taalgebruik, dien eerstens as bewys dat ' $n$ woord wel in ' $n$ taal bestaan en optree. By omvattende woordeboeke stel die samestellers daarvan hulle dit ten doel om diẹ volle inventaris van die taal se woordeskat in hulle woordeboeke weer te gee. In sulke woordeboeke verskyn daar dikwels leksikale items wat vir die gemiddelde woordeboekgebruiker heeltemal onbekend is. Hier dien sitate as bewysmateriaal van die bestaan van hierdie leksikale items. Dit geld veral gevalle waar ' $n$ woord die maaksel van 'n digter of skrywer is. Geeraerts en Janssens (1982: 18-19) noem dat voorbeelde bewys lewer daarvan dat ' $n$ bepaalde betekenis nie ' $n$ versinsel van die leksikograaf is nie.

Indien die woordeboekgebruiker 'n woord wat vir hom onbekend is met 'n sitaat daamaas in die woordeboek aantref, is hy nie net verseker van die feit dat die woord wel in die taal voorkom nie, maar ook in watter styl- en registervlakke dit tipies optree. Voorbeeldmateriaal is hier veral nuttig waar 'n woord 'n beperkte gebruikspektrum het.

Voorbeeldmateriaal dien ook op 'n tweede vlak as bewysmateriaal. Anderson, Goebel en Reichmann (1983: 29) wys daarop dat voorbeeldmateriaal alles wat dit in die woordeboekartikel voorafgaan, bewysbaar maak. Dit illustreer dus die gegewe sintaktiese, morfologiese, semantiese en grammatiese inligting. Hierdie funksie sluit dus aan by die daarstel van 'n wisselwerking tussen die verskillende tekssegmente om 'n eenheidskarakter in die woordeboekartikel te skep.

\section{Voorbeeldmateriaal het genererende krag}

Zgusta (1971: 264) noem dat 'n leksikograaf nooit volledig kan werk nie, en slegs enkele voorbeelde kan gee wat vir die woordeboekgebruiker as aansporing moet dien om ander uitings te vorm na analogie van die gegewe voorbeelde. Voorbeeldmateriaal help die woordeboekgebruiker om patroonmatigheid raak te sien en soortgelyke grammaties korrekte uitings te vorm. Dit help hom dus met enkodering. Voorbeelde moet dus met groot sorg gekies word om die woordeboekgebruiker te help by die vorming van nuwe uitings.

Voorbeeldmateriaal moet op verskeie vlakke verteenwoordigend wees van dit wat tipies in die taal optree. Hierdie funksie is veral by eentalige aanleerderwoordeboeke baie belangrik. Die niemoedertaalspreker kry al die inligting in die woordeboekartikel in die vreemde taal. Hy het dus nie die voordeel van 'n vertaling of omskrywing van die inligting in sy moedertaal nie.

In sy keuse van voorbeeldmateriaal moet die leksikograaf daarteen waak om te veel voorbeelde van afwykende, abnormale of atipiese taalgebruik te gee. Sulke voorbeelde kan die woordeboekgebruiker mislei en verwar. Dit is 
ook nie vir hom van veel waarde wanneer hy dit raadpleeg vir enkoderingsdoeleindes nie. Dit geld ook woordeboeke vir moedertaalsprekers.

Vergelyk die volgende voorbeeld wat by afoor in die Verklarende Handwoordeboek van die Afrikaanse Taal (voortaan HAT) optree: Van Gogh was afoor teen die einde van sy lewe. Hierdie voorbeeld dui eerder 'n moontlike as 'n tipiese gebruik van afoor aan. Die feit dat die sin lagwekkend is terwyl dit nie veronderstel is om dié effek op die leser te hê nie, is ' $n$ aanduiding daarvan dat dit as voorbeeldsin misluk. 'n Alombekende tipiese kombinasie soos ' $n$ afoor koppie sou hier 'n beter keuse wees, aangesien dit genererende krag sal hê. Die woordeboekgebruiker kan byvoorbeeld na analogie daarvan die naamwoordstuk 'n afoor beker vorm en suksesvol gebruik.

\section{Voorbeeldmateriaal illustreer sintaktiese verbindingsmoontlikhede van lemmas asook die beperkinge daarop}

Die optrede van sommige leksikale items is beperk tot bepaalde sinstipes. Hierdie inligting word met behulp van voorbeeldmateriaal geillustreer. By lemmas waarby daar ' $n$ beperking is op die sintaktiese omgewing waarin die woord kan optree, kan hierdie inligting as eksplisiete grammatiese inligting verskaf word. By kleiner woordeboeke, waar sulke inligting weens gebrek aan spasie nie eksplisiet aangebied kan word nie, vervul voorbeeldmateriaal ' $n$ baie belangrike funksie.

Hierdie funksie van voorbeeldmateriaal geld byvoorbeeld sekere adjunkte. Die woord allesbehalwe tree slegs in positiewe stelsinne op. In HAT word wel ' $n$ voorbeeldsin by allesbehalwe gegee, naamlik Hulle het my allesbehalwe goed ontwang. Die sin illustreer die korrekte optrede van hierdie adjunk. Dit is goeie leiding. Ter aanvulling van hierdie leiding sou eksplisiete inligting ook aan die gebruiker gegee kon word in die vorm van 'n etiket, naamlik slegs in positiewe stelsinne.

Nog 'n groep leksikale items waarvan die sintaktiese optrede beperk is, is neweskikkers. By sekere korrelatiewe neweskikkers kan slegs woorde as konjunkte optree; by ander woorddele, woorde en sinne. Hierdie inligting moet in die voorbeeldmateriaal weerspieël word. Vergelyk byvoorbeeld die korrelatiewe paar nóg...nóg. Hier kan twee tipes konjunkte optree, naamlik woorde en woorddele. Die volle gebruikspektrum van die lemma moet weerspieël word. By nog II in NW is daar twee voorbeelde, naamlik $H y$ het nóg kind nóg kraai en Nóg die een, nóg die ander. Dit is goeie leiding, aangesien dit toon dat 'n naamwoordstuk met slegs 'n enkele naamwoord asook ' $n$ uitgebreider naamwoordstuk as konjunkte kan optree. Hier moes egter nog 'n voorbeeld opgetree het, wat sou aandui dat woorddele ook as konjunkte van hierdie korrelatiewe neweskikkingspaar kan optree, byvoorbeeld Hy eet nóg vis-nóg herderspastei. 
8. Voorbeeldmateriaal illustreer die lemma se gebondenheid aan 'n kon-
teks

Hierdie funksie van voorbeeldmateriaal kan geklasssifiseer word as 'n pragmatiese funksie. Dit is ' $n$ funksie wat beperk is tot sitate uit die geskrewe en optekeninge uit die gesproke taal. Fox (1987: 141) toon aan dat dit belangrik is dat voorbeelde deel vorm van 'n samehangende stuk teks, aangesien taal nie bestaan uit ' $n$ reeks geïsoleerde sinne nie. 'n Nadeel van poëme is dat hulle dikwels veels te netjies afgeronde klein gehele is. In werklike taalgebruik kom daar egter sekere elemente voor wat verraai dat 'n sitaat deel vorm van 'n groter geheel. ' $n$ Voorbeeld hiervan is teksbindmiddels. Woorde soos en, daarna en toe verbind ' $\mathrm{n}$ stuk teks aan dit wat dit voorafgaan of dit wat daarop volg. Tydsadjunkte soos toe en daarop verbind ook stukke teks met mekaar om 'n groter geheel te vorm.

In omvattende woordeboeke word grootliks van sitate gebruik gemaak om werklike taalgebruik weer te gee. 'n Woordeboek soos die Woordeboek van die Afrikaanse Taal bevat talle gesiteerde voorbeelde wat illustreer'dat hierdie stukke teks oorspronklik deel gevorm het van 'n groter geheel. Vergelyk byvoorbeeld die volgende sitaat by $\mathbf{k l i t s}^{2}$, betekenisonderskeiding 1: Daarna kom die louwarm water, en 'n bietjie klits maak alles mooi deurmekaar. Die woordeboekgebruiker wat hierdie sitaat lees, kan duidelik sien dat hierdie sin nie 'n geïsoleerde sin is nie, maar uit ' $n$ groter stuk teks geneem is.

\section{Voorbeeldmateriaal onderskei die lemma van ander semanties ver- wante lemmas}

Indien die leksikon van ' $n$. taal beskou word as 'n netwerk van betekenisbetrekkinge, moet daar aanvaar word dat geen leksikale item los staan van alle ander leksikale items nie. In die definiens word dikwels van leksikale betrekkinge soos sinonimie, antonimie en hiponimie gebruik gemaak om 'n lemma te definieer. Voorbeeldsinne verrig 'n soortgelyke funksie. Leksikale items wat aan 'n lemma verwant is, tree dikwels in voorbeeldșinne onder daardie lemma op. In sulke voorbeeldsinne word daar aan die woordeboekgebruiker riglyne gegee ten opsigte van die korrekte gebruik van meer as een leksikale item. Hierdie tipe voorbeeld verskaf nie net nuttige sintaktiese leiding nie, maar is boonop ekonomies.

Hierdie funksie van voorbeeldsinne help om die sintaktiese optrede van 'n lemma te laat aansluit by dié van ander lemmas deurdat die leksikon van 'n taal beskou word as deel van 'n netwerk van betekenisbetrekkinge. Vir verdere inligting oor die struktuur van die leksikon, vergelyk De Stadler (1989: 52).

By kuns in NW kom die volgende voorbeeld onder die eerste betekenisonderskeiding voor: Fotografie kan ook kuns wees. In hierdie sin is fotografie 'n 
hiponiem van die superordinaat kuns. Die twee leksikale items val in dieselfde semantiese veld, naamlik dié van kunsvorme.

By gelowige in HAT kom 'n soortgelyke voorbeeld voor: ' $n$ Mens is of ' $n$ gelowige of ' $n$ ongelowige. In hierdie sin is daar 'n semantiese verhouding van opposisie tussen gelowige en ongelowige. Dit gaan hier oor 'n komplementêre paar.

\section{Slotwoord}

Voorbeeldmateriaal kan 'n belangrike bydrae lewer tot die geslaagdheid van 'n woordeboekartikel mits dit op doeltreffende wyse gebruik word om onderlinge samehang te bewerkstellig tussen die verskillende mikrostrukturele inligtingstipes in die artikel. Dit is noodsaaklik dat elke leksikograaf ingestel sal wees op die behoeftes van woordeboekgebruikers om sy woordeboek gebruikersvriendeliker te maak. In sy hantering van voorbeeldmateriaal moet die leksikograaf altyd in gedagte hou dat voorbeeldmateriaal 'n verteenwoordigende monster van werklike taalgebruik moet wees. Sowel die gesproke as die geskrewe taal moet in sy voorbeeldmateriaal verteenwoordig word. Sitate en poëme kan met groot sukses vir hierdie doel aangewend word.

\section{Verwysings}

Anderson, R.R., U. Goebel en O. Reichmann. 1983. Probeartikel zum frühneuhochdeutschen Wörterbuch. Wiegand, H.E. (Red.). 1983: 11-52.

De Stadler, L.G. 1989. Afrikaanse semantiek. Johannesburg: Southern.

De Villiers, M. e.a. 19877. Nasionale Woordeboek. Kaapstad: Nasou.

Fox, G. 1987. The Case for Examples. Sinclair, J.M. (Red.). 1987: 137-149.

Geeraerts, D. en J. Janssens. 1982. Wegwijs in woordenboeken. Assen: Van Gorcum.

Gouws, R.H. 1989. Leksikografie. Kaapstad: Academica.

Hyldgaard-Jensen, K. en A. Zettersten (Reds.). 1988. Symposium on Lexicography III. Tübingen: Max Niemeyer.

Johnson, S. 18069. A Dictionary of the English Language. Londen: Luke Hansard.

Lombard, F.J. 1992. Voorbeeldmateriaal in woordeboeke. Lexikos 2: 148-164.

Odendal, F.F. 19792. Verklarende Handuoordeboek van die Afrikaanse Taal. Doomfontein: Perskor.

Procter, P. (Red.). 19842. Longman Dictionary of Contemporary English. Essex: Longman.

Sinclair, J.M. (Red.). 1987. Looking Up. Londen: Collins.

Wiegand, H.E. (Red.). 1983. Germanistische Linguistik 1-4/82. Hildesheim: Georg Olms Verlag.

Wiegand, H.E. 1988. Überlegungen zu einer Theorie der lexikographischen Sprachbeschreibung. Hyldgaard-Jensen en Zettersten (Reds.). 1988: 35-72.

Zgusta, L. 1971. Manual of Lexicography. Den Haag: Mouton. 


\section{Geraadpleegde werke}

Abraham, W. 1974. Terminologie zur neueren Linguistik. Tübingen: Max Niemeyer.

Gouws, R.H. 1982. Die sknapping van ident ieke stukke in Afrikeanse meweskikkingstontruksies. Ongepubliseerde D.Litt.-proefskrif. Universiteit van Stelenbosch.

Hartmann, R.R.K. (Red.). 1983. Lexicography: Principles and Practice. Londen: Academic Press.

Landau, S.I. 1984. Dictionaries: The Art and Craft of Lexicography. New York: The Scribner Press.

Lemmens, M. en H. Wekker. 1986. Grammar in English Leamers' Dictionaries. Tübingen: Max Niemeyer.

Levinson, S.C. 1983. Pragmatics. Cambridge: Cambridge University Press.

Ponelis, F.A. 1979. Afrikanse sintaksis. Pretoria: J.L. Van Schaik.

Wolski, W. Partikellexikographie. 1986. Tübingen: Max Niemeyer. 